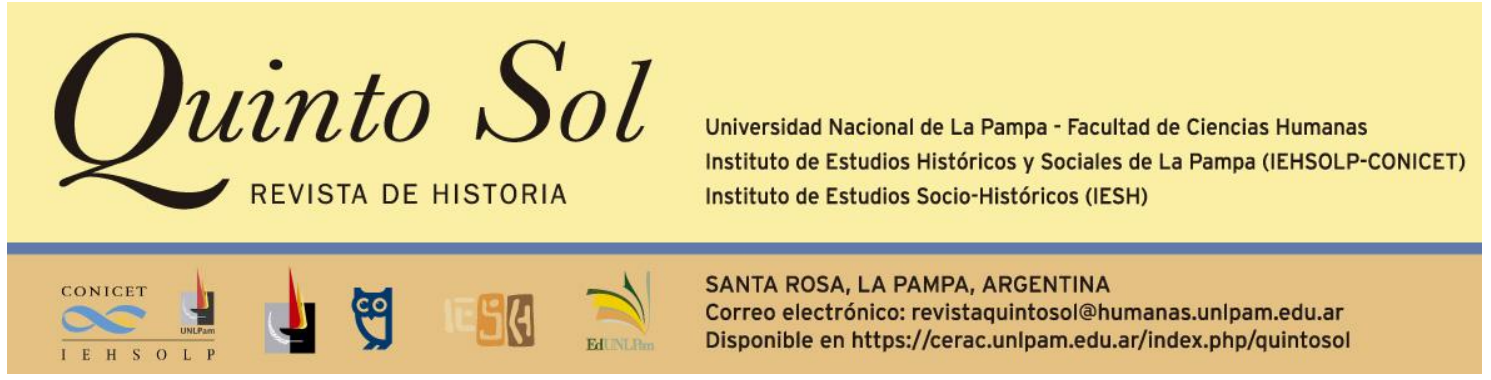

Quinto Sol, vol. 25, n 3, septiembre-diciembre 2021, ISSN 1851-2879, pp. 1-4

http://dx.doi.org/10.19137/ qs.v25i3.5556

Esta obra se publica bajo licencia Creative Commons 4.0 Internacional. (Atribución-No ComercialCompartir Igual)

\title{
Irina Polastrelli. Castigar la disidencia. Juicios y condenas en la elite dirigente rioplatense, 1806/1808- 1820. Academia Nacional de la Historia, 2019, 356 páginas.
}

\section{Laura Cucchi}

Consejo Nacional de Investigaciones Científicas y Técnicas. Instituto de Historia Argentina y Americana "Dr. Emilio Ravignani"

Universidad de Buenos Aires. Facultad de Filosofía y Letras. Departamentos de Historia y Filosofía Argentina

Correo electrónico: Icucchi@filo.uba.ar

Acreedor del Premio de la Academia Nacional de la Historia a las Obras Inéditas (2015-2016) y publicado como resultado en 2019, Castigar la disidencia presenta una versión revisada de la tesis doctoral defendida por Irina Polastrelli en la Universidad Nacional de Rosario durante 2016. En ella, la autora abordó un problema medular de la política argentina: la conflictividad en la tramitación de la oposición en el momento mismo en que la crisis del orden colonial y la disrupción revolucionaria inauguraban la era de la política en el Río de la Plata. Su investigación explora los mecanismos judiciales para procesar la conflictividad política en el período que va desde la crisis desatada por las Invasiones Inglesas en 1806 y 1807 hasta la disolución del poder central en 1820, revisando, de manera crítica, la literatura elaborada por la historia tradicional del derecho que ha señalado, de manera anacrónica, que esa conjunción de la justicia y la política atentaba contra la independencia de los poderes públicos.

Como la autora señala en la introducción, las preocupaciones por la gobernabilidad y la domesticación del conflicto estuvieron anudadas a lo largo del período al anhelo por la recomposición del cuerpo político, que tanto las autoridades 
coloniales como las dirigencias revolucionarias entendieron como fracturado por la inestabilidad abierta con la respuesta a las Invasiones Inglesas, y luego, por las disidencias sostenidas sobre el rumbo que debía seguir el proceso revolucionario. Es decir que los mecanismos por los cuales se intentó pacificar la política en esos años estuvieron siempre informados por una forma particular de entender las disputas y la disidencia: como elementos extraños y accidentales, no constitutivos, del orden político (colonial o revolucionario) que buscaba preservarse.

Polastrelli navega el marasmo que trajo la inestabilidad entre 1806 y 1810, así como la nueva competencia por el poder posterior, en el telón de fondo de la enorme transformación de la política y de las elites dirigentes de esos años. Su acercamiento a una dimensión de esa experiencia -la de los procesos judiciales para castigar a los disidentes-, le permite analizar aspectos mucho más vastos de la dinámica política e institucional de esa etapa, como el funcionamiento de la división de poderes o del principio de representación. En efecto, la lente que va guiando su indagación ofrece un provechoso mirador para comprender cómo las dirigencias entendían y ejercitaban la política en esos años de profundas redefiniciones en que estaba en juego, en definitiva, cuáles eran sus reglas, sus espacios y sus mecanismos legítimos.

El acercamiento a ese objeto es realizado con un prisma que nace del cruce entre las propuestas de la historia de la justicia, la historia crítica del derecho y la llamada nueva historia política. El corpus de indagación, a su vez, está formado por sumarios militares, juicios de residencia y otros juicios llevados adelante por comisiones especiales, que fueron entablados contra los más encumbrados miembros de la elite dirigente bajo la acusación de que atentaban contra el orden político y apelando a variadas fuentes jurídicas. El análisis y la descripción densa de los diferentes procesos sostenidos en el ocaso de la dominación colonial y la primera década revolucionaria va enhebrando el relato de esta obra que, al tiempo que avanza en los derroteros de la crisis y la revolución, va iluminando los diferentes mecanismos de persecución judicial de la oposición política, y con ello, las cambiantes valoraciones sobre la disidencia.

El primer capítulo pone el foco en los años que van desde las Invasiones Inglesas hasta el estallido de la revolución. Analiza en esas páginas la persecución de que fueron objeto Saturnino Rodríguez Peña, Diego Paroissien, Juan Martín de Pueyrredón y los participantes de la asonada contra el virrey el $1^{\circ}$ de enero de 1809 , acusados todos de impulsar planes "independentistas" en un escenario convulsionado por la inestabilidad abierta en el Río de la Plata en 1806 y profundizada por los efectos de la crisis monárquica de 1808. El análisis de esos procesos ilumina el uso plurívoco del concepto de independencia, que fue utilizado y "torsionado" en esos años con valoraciones positivas y negativas, en ocasiones por parte de los mismos actores, como muestra la defesa de Castelli de Paroissien, y de cara a cuestiones diversas como la relación de las colonias con el rey o con el invasor francés.

El segundo capítulo deja atrás los delitos de lesa majestad con que se había buscado inculpar a los disidentes durante la crisis del orden colonial, y se interna en los procesos entablados hacia quienes fueron acusados de conspirar contra la causa de la revolución cometiendo con ello delito de lesa patria: Santiago de Liniers y Martín de Álzaga, los obispos Orellana y Videla del Pino y aquellos perseguidos por el Tribunal de Seguridad Pública de 1811. Allí, la autora presenta las características de los procesos, ofrece un contrapunto de las similitudes y divergencias, y conecta la diversidad en la dureza de los castigos aplicados a las conveniencias cambiantes para la supervivencia 
del nuevo orden: castigos ejemplares en los casos de Liniers y Álzaga, pero menos severos hacia las faltas de las autoridades eclesiásticas cuya persecución podía ofender la religiosidad de la población. A través de esos tres tipos de procesos, Polastrelli explora, además, los cambios que estaba experimentando en esa hora temprana de la revolución el concepto de patria, en el marco de la organización de una visión acerca de la disidencia que se fue montando sobre la delimitación de una oposición entre españoles y americanos. Pero muestra, también, cómo esos mecanismos de vigilancia y persecución de las oposiciones fueron dirigidos no solo contra los enemigos "externos" de la revolución, sino cada vez más para enfrentar el disenso en el interior del núcleo dirigente.

El capítulo tres presenta el escenario en el cual la frontera entre esos dos casos se fue borrando, conforme se hizo patente que la oposición política no desaparecía con la mera supresión de movimientos contrarrevolucionarios. Allí, la autora examina la persecución de la disidencia que acompañó los crecientes enfrentamientos entre saavedristas y morenistas y la apuesta que se hizo para suturar, por vía judicial, lo que se entendía como heridas que desgarraban el cuerpo político. El apartado aborda tres momentos sucesivos como vía de entrada a los cambios en los modos en que se buscó establecer (o en la mirada de los contemporáneos, reestablecer) la unidad perdida. Primero, las disputas dentro de la dirigencia revolucionaria en 1810-1811 que fueron dirimidas en parte no menor por vía judicial. Segundo, aquellas que acompañaron el triunfo de la Logia Lautaro (1812-1815) que evitó esa vía y optó por la suspensión de las garantías. Y, por último, los años que van de la declaración de la Independencia a la disolución del poder central en los cuales se alternó entre las dos estrategias anteriores.

El tercer capítulo reorienta el foco hacia el análisis de las relaciones entre guerra y política en el ámbito de la justicia y examina los sumarios militares contra Manuel Belgrano, Juan José Castelli y Antonio González Balcarce por su rol en las derrotas de la Expedición al Paraguay y al Alto Perú. La autora muestra las conexiones del inicio, desarrollo y cierre de dichos sumarios con las demandas políticas de cada momento, como la presión popular que llevó a entablar la causa contra Belgrano, y la preocupación del Triunvirato para cerrar la causa de Balcarce por la derrota de Huaqui y evitar más fracturas en el escenario político. Sostiene que la desigual atención que recibieron por parte de las autoridades se vinculaba con la importancia relativa de cada una de esas dos regiones en el avance de la revolución.

El juicio a las responsabilidades, no ya militares sino políticas, es abordado en el cuarto capítulo a través de tres casos: la adaptación y reformulación de la institución de la Residencia por parte de la Asamblea del año XIII que condenó a Cornelio Saavedra y a Joaquín Campana. El juicio impulsado por el Cabildo contra el sector alvearista en 1815 por el delito de facción. Por último, el del gobernador de Buenos Aires, Manuel de Sarratea, contra los miembros del Directorio y del Congreso en 1820 por el delito de alta traición en función de sostener planes monárquicos. El análisis muestra, de manera muy clara, los desafíos de delinear mecanismos inéditos de control de abusos o arbitrariedades en el ejercicio del poder. También, los modos de definir los contornos de un control del soberano sobre los gobernantes cuando estaba en disputa precisamente cuál era el sujeto de imputación soberana, e ilumina cómo de la mano del uso de esos mecanismos, se expresaban e informaban los nuevos valores y prácticas relativos a la actividad y a la comunidad políticas. 
Finalmente, en el epílogo, la obra da cuenta del giro en el tratamiento de la disidencia que supuso la ley de olvido impulsada por la provincia de Buenos Aires en 1821, que cerró las causas judiciales entabladas en la década precedente y levantó las penas impuestas. Estas, en general, habían sido relativamente leves en comparación con otros escenarios hispanoamericanos, mostrando, a juicio de la autora, que su objeto no era la eliminación del enemigo sino más bien su neutralización política. Con todo, ese viraje y la apuesta por la reconciliación, nacían del mismo impulso que la judicialización previa del disenso: el empeño incesante en dotar de unidad al cuerpo político que se entendía como precondición para la estabilidad.

En suma, este estudio contribuye de manera decidida al conocimiento de los cambiantes caminos transitados por los contemporáneos para procesar la disidencia en los albores del siglo XIX. Como sabemos, el Río de la Plata compartió esas dificultades con el resto las Américas, lanzadas a la aventura de la república, pues en todo el continente predominó un recelo frente a la oposición política. Por ese motivo, la selección temporal elegida por la autora invita a volver sobre las convergencias y divergencias en las formas de concebir y procesar las diferencias políticas entre el orden colonial y el republicano. Polastrelli, en esa línea, señala que la apuesta por los diferentes modos de zanjar las disputas resultó, en esos años, estratégica e intuitiva en lugar de ideológica, y sugiere que esa asonancia se conectó a que, en esos quince años abordados, todos los actores, a pesar de las diferencias de signo político, compartían un supuesto más profundo que se vinculaba a visiones monistas de la comunidad política. Si dichos puntos de partida fueron similares a otros espacios, la particularidad del Río de la Plata durante este período fue, en cambio, la moderación en la persecución de los opositores, que se conectó tanto con la ausencia de fuertes amenazas externas como con la cohesión, con todo, del núcleo dirigente. La modificación de esas condiciones en las décadas siguientes alteró también el tratamiento de la disidencia y, de manera más general, la dinámica del antagonismo político, como señala en el epílogo. De esta forma, el estudio de Polastrelli proyecta sus interrogantes sobre otras etapas, invitándonos a periodizar y a pensar las discontinuidades en la tolerancia del disenso y en el tratamiento de la oposición política. 